\title{
Envelope protein gene based molecular characterization of Japanese encephalitis virus clinical isolates from West Bengal, India: a comparative approach with respect to SA14-14-2 live attenuated vaccine strain
}

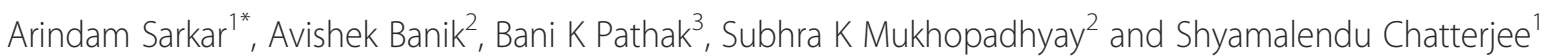

\begin{abstract}
Background: Increasing virulence of Japanese encephalitis virus (JEV), a mosquito-borne zoonotic pathogen is of grave concern because it causes a neurotrophic killer disease Japanese Encephalitis (JE) which, in turn, is responsible globally for viral acute encephalitis syndrome (AES). Despite the availability of vaccine, JE/AES cases and deaths have become regular features in the different rural districts of West Bengal (WB) state, India, indicating either the partial coverage of vaccine or the emergence of new strain of JEV. Therefore, a study was undertaken to characterize and compare the complete envelope (E) protein gene based molecular changes/patterns of JEVs circulating in WB.

Methods: Total of 98 AES case-patients' samples were tested to detect the presence of JEV specific immunoglobulin M (IgM) antibody by Mac-ELISA method. Only JEV IgM negative samples with a history of $\leq 3$ days' illness were screened for virus isolation and RT-PCR. E gene sequences of JEV isolates were subjected to molecular phylogeny and immunoinformatics analysis.

Results: Present study confirmed JEV etiology in $39.7 \%$ and $29.1 \%$ of patients presenting $\leq 15$ days' febrile illness, as determined by Mac-ELISA and RT-PCR respectively. Phylogenetic analysis based on complete E gene sequences of JEV isolates showed the co-circulation of JEV genotype I (GI) with genotype III (GIII). This study also demonstrated that isolate-specific crucial amino acid substitutions were closely related to neurovirulence/neuroinvasiveness of JE. On the basis of immunoinformatics analysis, some substitutions were predicted to disrupt T-cell epitope immunogenicity/antigenicity that might largely influence the outcome of vaccine derived from JEV GIII SA14-14-2 strain and this has been observed in a previously vaccinated boy with mild JE/AES due to JEV GI infection.

Conclusions: Based on molecular evolutionary and bioinformatic approaches, we report evolution of JEV at a local level. Such naturally occurring evolution is likely to affect the disease profile and the vaccine efficacy to protect against JEV GI may demand careful evaluation.
\end{abstract}

Keywords: Japanese encephalitis virus, Envelope protein gene, Molecular phylogeny, Genotype III, Genotype I, Homology modeling, Hydrophilicity, T-cell epitope, West Bengal

\footnotetext{
* Correspondence: arimicro.sarkar@gmail.com

${ }^{1}$ ICMR virus unit, GB- 4, 1st Floor, ID \& BG Hospital, 57, Dr. S. C. Banerjee

Road, Beliaghata, Kolkata 700010, West Bengal, India

Full list of author information is available at the end of the article
} 


\section{Background}

The flaviviruses persist as causative agents for a wide range of human related infectious diseases worldwide. However, the most common causes of Acute Encephalitis Syndrome (AES) are associated with the Japanese encephalitis virus (JEV) serocomplex that includes Murray Valley encephalitis virus (MVEV), West Nile virus (WNV), St. Louis encephalitis virus (SLEV), and prototypical member JEV within/belonging to the Flavivirus genus under the family Flaviviridae [1,2]. The mosquito-borne JEV is the sole etiologic agent of Japanese encephalitis (JE); a neurotropic killer disease being one of the major causes of viral acute encephalitis in human. Since the isolation of this virus in Japan in 1935 [3], it has been detected worldwide becoming a major public health problem. Worldwide case-fatality rate of JE was recorded to be $30 \%$ approximately with $30-50 \%$ of survivors having irreversible neuropsychiatric sequelae [4].

The natural transmission cycle of JEV involves an enzoonotic (sylvatic) mosquito-bird-mosquito and/or mosquito-pig-mosquito cycle; primarily involving Culex spp. mosquitoes as primary vectors [5], wading birds as reservoir host [6], pigs as amplifying host [7] and Humans are the accidental "dead end" hosts [8].

Like other flaviviruses, JEV, an enveloped positivesense single stranded RNA ( $\sim 11 \mathrm{~kb}$ in length) virus contains single open reading frame (ORF) encoding a polyprotein that is processed into three structural $(C, M$, and E) and seven nonstructural (NS1, NS2A, NS2B, NS3, NS4A, NS4B, and NS5) proteins, flanked by $5^{\prime}$ and 3'-non-translated regions (NTRs) [9-11]. Among the three structural proteins, the envelope $(E)$ protein is considered as the most antigenic part of the viral genome and is found to be involved in the majority of the biological properties of the virus, such as binding to the cell receptor, inducing immunological responses (neutralization, passive protection and antibody dependent enhancement), virion assembly and fusion activity at low $\mathrm{pH}[12,13]$. In addition, the amino acid substitutions in E protein have a major role in determining the neuorovirulence or neuroinvasiveness [14]. The nucleotide sequence of full-length $\mathrm{E}$ gene of JEV is an established/reliable phylogenetic marker because this region has got no selective pressure supporting obscure long-term evolutionary relationship. Based on the nucleotide sequence of $\mathrm{E}$ gene, JEV can be divided into five distinct genotypes [15]. Mostly genotype III (GIII) is circulated in the Southeast Asian countries, including Japan, South Korea, China, Taiwan, Vietnam, Philippines, and India [2]. However, it has been recently documented that GIII is replaced by genotype I (GI) in South Korea, Thailand and China [16].

In India, the existence of JEV was first reported serologically in 1954 [17]. However, the disease was first recognized in India at Vellore (in the state of Tamil Nadu) in 1955 [18]. Since then, epidemics of JE in different states have been recorded $[19,20]$. It was mentioned that genotype III is predominant in India, but recently genotype I has been introduced in this country $[16,21]$.

The state of West Bengal (WB) is situated at the eastern part $\left(23^{\circ} 00^{\prime} \mathrm{N}, 87^{\circ} 00^{\prime} \mathrm{E}\right)$ of India with an area and population of $88,752 \mathrm{~km}^{2}$ and 91,347,736 respectively bounded on the north by Sikkim and Bhutan, on the east by Assam and Bangladesh, on the south by the Bay of Bengal and on the west by Orissa, Bihar, Jharkhand and Nepal [22]. In 1973 JE outbreak was first recorded in the rural districts of Burdwan and Bankura in the state of WB where 700 cases and 300 deaths were reported [23,24]. Thereafter, several JE outbreaks took place in the state [25-27]. As per published literature, the State Health Department, Govt. of WB has conducted vaccination programme against JE in different rural districts of WB [28]. But still sporadic JE/AES cases and deaths are being reported every year from the state [29]. The people of the state dependent on cultivation work in the water-logged paddy fields which serve as congenial home for mosquito breeding [22]. Moreover, to raise their economic status they usually take up piggery and mini-poultry in their own hut bringing animals in their close association. In addition, environmental factors of this state also favor JEV transmission [22]. Moreover, the reports of JE incidences or endemicity of JE in the state might be the indications of partial vaccination although the emergence of mutated/new strain of JEV could not be excluded.

The present study was carried out to characterize the genetic variation in the E protein of JEV circulating in the WB state and to observe the difference and/or crucial amino acid changes in E protein of the WB isolates in comparison with SA14-14-2 live attenuated vaccine strain in order to enable us to understand the variations in antigenic and neutralizing properties of different JEV WB isolates, followed by analyzing the molecular impact of amino acid substitutions on envelope protein structure of those isolates in relation to disease severity.

\section{Methods}

\section{Case enrollment and sample collection}

Clinically diagnosed 98 AES cases (28 from Malda, 15 from Hooghly, 25 from Midnapore, 11 from Birbhum, 10 from Howrah and 9 from South 24 Parganas) of all age groups having high grade fever for $\leq 15$ days with the symptoms viz. headache, vomiting, unconsciousness/ coma, convulsion/seizure, abnormal movements, delirium, altered sensorium, neck rigidity, presence of kernig's sign etc. were admitted in abovenoted 6 district government hospitals in the state of WB from August to December both in 2011 and 2012. The study was duly 
approved by the joint ethical committee of ICMR (Indian Council of Medical Research) virus unit and NICED (National Institute of Cholera and Enteric Diseases), Kolkata, India. Informed consents were obtained in prescribed proforma from the patients or legal guardians or relatives of the patients before the collection of the samples. A total of 98 [62 serum and 36 cerebrospinal fluid (CSF)] samples were collected and/or referred from the above said clinically diagnosed AES case-patients to ICMR Virus Unit, Kolkata, maintaining the cold chain, for the detection of JEV infection. Cerebral malaria and bacteriological etiology were ruled out on the basis of clinical observations by the physicians of the hospitals concerned. All sera and CSF samples were stored in aliquots at $-80^{\circ} \mathrm{C}$ until use.

\section{IgM-capture ELISA}

All the samples were tested to detect the presence of JEV specific immunoglobulin M (IgM) antibody using JEV IgM-capture ELISA test kit (supplied by National Institute of Virology, Pune, India) based on the manufacturers' protocol. Optical density (O.D) was measured at $450 \mathrm{~nm}$ using an ELISA reader (Titertek Multiskan Plus, Lab systems Finland, Type-314).

\section{Isolation of virus from samples}

Only 24 JEV IgM negative samples with a history of $\leq 3$ days' illness were screened and $200 \mu$ l of each of them was inoculated to $\mathrm{C} 6 / 36$ cell line for virus isolation as previously described [28]. The tissue culture fluids were collected from the samples producing prominent cytopathic effect $(\mathrm{CPE})$, and centrifuged at $1000 \times \mathrm{g}$ for 5 minutes and the supernatants of tissue culture fluids (STF) were kept in aliquots at $-80^{\circ} \mathrm{C}$ till the isolation/extraction of viral RNA, followed by $\mathrm{E}$ gene amplification through RT-PCR test.

\section{RNA extraction, E gene amplification and nucleotide sequencing}

Viral RNA was extracted from $140 \mu \mathrm{l}$ of STF utilizing QIAamp RNA viral kit (Qiagen, GmbH, Hilden, Germany), following the manufacturer's instructions. Extracted/purified RNA was applied as template for cDNA synthesis using avian myeloblastosis virus (AMV) reverse transcriptase (RT) and the JEV E gene specific reverse primer. In brief, the target RNA was converted to cDNA in $25 \mu \mathrm{l}$ mixture volumes containing the following components: $11.76 \mu \mathrm{l}$ of $\mathrm{dH}_{2} \mathrm{O}$ (MiliQ grade), $5 \mu \mathrm{l}$ of $5 \times$ AMV RT buffer, $1.6 \mu \mathrm{l}$ of $10 \mathrm{mM}$ deoxynucleotide triphosphates $\left(\mathrm{dNTP}_{\mathrm{S}}\right)$ (Invitrogen, USA), $0.1 \mu \mathrm{l}$ of $0.1 \mathrm{M}$ dithiothreitol (DTT) (Promega, USA), $1.5 \mu \mathrm{l}$ of $10 \mu \mathrm{M}$ JEV E gene specific reverse primer [28], $0.04 \mu \mathrm{l}$ of $10 \mathrm{U} / \mu \mathrm{l}$ AMV RT (Promega, USA) and $5 \mu \mathrm{l}$ of RNA (50 pg to $1 \mu \mathrm{g}$ ). The reaction mixture was allowed to cDNA synthesis for $1 \mathrm{~h}$ at $42^{\circ} \mathrm{C}$. The cDNA was subsequently used for polymerase chain reaction (PCR) amplification in the total of $20 \mu$ reaction mixture that was prepared using $9.3 \mu \mathrm{l}$ of $\mathrm{dH}_{2} \mathrm{O}$ (MiliQ grade), $2 \mu \mathrm{l}$ of $10 \times$ DreamTaq DNA polymerase buffer, $0.5 \mu \mathrm{l}$ of $10 \mathrm{mM}$ deoxynucleotide triphosphates $\left(\mathrm{dNTP}_{\mathrm{S}}\right)$ (Invitrogen, USA), $1.5 \mu \mathrm{l}$ of $10 \mu \mathrm{M}$ JEV E gene specific primer pairs [28], $0.2 \mu \mathrm{l}$ of $5 \mathrm{U} / \mu \mathrm{l}$ DreamTaq DNA polymerase (Fermentas Inc., USA) and $5 \mu$ l of cDNA. PCR reaction conditions were as follows: initial denaturation at $94^{\circ} \mathrm{C}$ for $5 \mathrm{~min}$, followed by 35 cycles of denaturation (at $94^{\circ} \mathrm{C}$ for $30 \mathrm{~s}$ ), primer annealing (at $67^{\circ} \mathrm{C}$ for30 s), and primer extension (at $72^{\circ} \mathrm{C}$ for $1 \mathrm{~min} 30 \mathrm{~s}$ ). Then a final extension step was carried out at $72^{\circ} \mathrm{C}$ for $5 \mathrm{~min}$. The PCR products were separated by electrophoresis on $1 \%$ agarose gel, stained with ethidium bromide.

RT-PCR amplicons were purified with the help of the Qiagen gel extraction kit (Qiagen, GmbH, Hilden, Germany), according to the manufacturer's protocol and subjected to direct sequencing using the BigDye Terminator Cycle Sequencing Ready Reaction Kit (Applied Biosystems, Foster City, CA, USA), in accordance with manufacturer's specifications. The products were purified by ethanol precipitation and were analyzed by an automated DNA sequencer, 3130XL Genetic Analyzer (PE Applied Biosystems, Foster city, CA, USA). The freely available Finch TV software (http://www.geospiza.com) was used to edit and correct the 1,500 nucleotides which generated complete $\mathrm{E}$ gene sequences of JEV isolates. Those sequences were subjected to BLAST search.

\section{Multiple sequence alignment (MSA) and phylogenetic analysis}

The E gene sequences of JEV strains/isolates used in MSA and phylogenetic analysis in this study were listed in Additional file 1. MSA and phylogenetic analysis were performed by CLUSTALW (http://www.ebi.ac.uk/Tools/ clustalw2/index.html) and MEGA version 5.0 software (http://www.megasofteware. net). The phylogenetic tree was constructed by the neighbor-joining method, tested with Kimura 2-parameter model and evaluated by 1000 bootstrap pseudo replicates. The strain MVEV-1-51 was used as an out group for generating the rooted tree. Moreover, the structure-based MSA of JEV isolates with respect to SA14-14-2 vaccine strain were analyzed by an online server named Porter (http://www.distill.ucd.ie/ porter/) to confirm the alteration of $\mathrm{E}$ protein secondary structure regarding disease severity.

\section{Mapping of amino acid substitutions}

Amino acid sequences were deduced from nucleotide sequences of the JEV isolates by Transeq (http://www.ebi. ac.uk/Tools/emboss/transeq/). The comparisons were 
made to identify the JEV isolates-specific amino acid substitutions in relation to JEV SA14-14-2 vaccine strain and were subsequently mapped onto the predicted 3-dimensional structures of isolate-specific E protein, as modelled based on predicted similarities to the homologous (95.8\% - 97.8\% identity) E protein of JEV SA14-14-2 vaccine strain [PDB:3P54] using ESyPred3D web server (http://www.fundp.ac.be/sciences/biologie/urbm/bioinfo/ esypred/). Finally, the predicted JEV isolate-specific E protein structures were viewed and manipulated with the help of PyMol software (http://www.pymol.org/).

\section{T-cell epitope prediction}

T-cell epitopes of the JEV isolate-specific structural E proteins were predicted using the EpiJen online server (http://www.ddg-pharmfac.net/epijen/) with respect to JEV SA14-14-2 vaccine strain. The isolate-specific amino acid sequences of $\mathrm{E}$ protein were put to use as input to EpiJen including JEV SA14-14-2 vaccine strain and the server was run in the default mode. The appropriate proteasomal and tap cut-off values were selected during epitope predictions for the 18 different HLA alleles.

\section{Results}

Serology, virus isolation and RT-PCR

Out of 98 samples, only 39 (39.7\%) were reactive to JEV specific IgM antibody, of which $24(61.5 \%)$ and 15 (38.4\%) samples were CSF and serum respectively. Of the remaining 59, only $24 \mathrm{JEV}$ IgM negative samples having the history of $\leq 3$ days of febrile illness were screened and subsequently subjected to tissue culture for virus isolation. This resulted in 11 samples producing prominent CPE (characterized by the roundening of cells, increased granularity and vacuolation, followed by cell death and disruption of the monolayer by detachment of the dead cells) of which only 7 (29.1\%) samples consisting of 5 (71.4\%) from CSF and 2 (28.5\%) from serum were determined to be JE with positive findings of viral RNA by RT-PCR test.

The basic characteristics of the patients from whom the samples were collected and selected/subjected to tissue culture for virus isolation, were presented in Table 1. The patients from the districts of Midnapore, Malda, Birbhum, Howrah and South 24 Parganas in WB state were all pediatric-adolescents, with an average age of 8 13 years whereas the patients belonging to Hooghly district were all adults, with an average age of 47 years. The summarized data of the patients from whom the viruses were isolated in the study was depicted in Table 2.

However, we have a total of 46 (39 IgM + 7 RT-PCR positive) JE cases representing $46.9 \%$ of 98 cases. Out of 46 cases, 33 (27 IgM +6 RT-PCR positive) were pediatric-adolescents (71.7\%) and remaining 13 (12 IgM + 1 RT-PCR positive) were found to be adult cases (28.2\%).
Table 1 Basic characteristics of the patients whose samples were screened for virus isolation in this study

\begin{tabular}{|c|c|c|c|c|}
\hline \multirow[t]{2}{*}{ Study area } & \multirow{2}{*}{$\begin{array}{l}\text { No. of } \\
\text { patients }\end{array}$} & \multicolumn{2}{|c|}{ Sex } & \multirow{2}{*}{$\frac{\text { Average age }}{\text { (Years) (Range }}$} \\
\hline & & Male & Female & \\
\hline Midnapore, West Bengal & 7 & 4 & 3 & $8(3-13)$ \\
\hline Hooghly, West Bengal & 3 & 2 & 1 & $47(39-55)$ \\
\hline $\begin{array}{l}\text { South } 24 \text { Parganas, } \\
\text { West Bengal }\end{array}$ & 3 & 2 & 1 & $12(3-17)$ \\
\hline Howrah, West Bengal & 1 & 0 & 1 & $13-$ \\
\hline Malda, West Bengal & 5 & 3 & 2 & $12(7-16)$ \\
\hline Birbhum, West Bengal & 5 & 3 & 2 & $10(5-16)$ \\
\hline
\end{tabular}

Moreover, the occurrence of JEV infection was recorded for the months of August to October in 2011 and 2012, with the maximum number of cases (71.4\%) observed in September in 2 consecutive years.

Molecular phylogeny and sequence analysis of isolates The Figure 1 represented the phylogenetic tree derived from $7 \mathrm{E}$ gene sequences of JEV isolates along with 40 wild-type JEV strains, including 11 from India and 29 from worldwide (Additional file 1). Phylogram showed 6 E gene sequences of the isolates [GenBank:KC526869KC526871 and KC802020-KC802022] belonging to GIII and comprising 98\%-100\% nucleotide similarity with each other and 93\%-98\% nucleotide similarity with other Indian GIII strains, having the highest similarity (97\%98\%) with Indian P20778 strain [GenBank:Z34096] and those GIII E gene sequences also amounted to $95 \%-96 \%$ nucleotide similarity with GIII SA14-14-2 vaccine strain [GenBank:D90195]. On the other hand, 1 E gene sequence of another isolate [GenBank:KC526872] belonging to GI that was most similar (96\%) with Japanese GI strain Ishikawa [GenBank:AB051292], followed by $94 \%$ nucleotide similarity with other Indian GI isolate JEVGKP-0945054 [GenBank:HM156572] and also having $87 \%$ nucleotide similarity with above said vaccine strain. Above all, the E gene nucleotide sequences of GIII isolates comprised 89\%-90\% nucleotide identity with GI isolate.

The isolates IND/11/WB/JEV48 [GenBank:KC802020] and IND/11/WB/JEV49 [GenBank:KC802021] were identical (having 100\% nucleotide similarity) with isolate IND/11/WB/JEV46 [GenBank:KC526869] and all of them showed same clinical outcome in the patient 4,5 and 2 (Table 2). Moreover, $100 \%$ nucleotide similarity was also observed in between the isolate IND/12/WB/ JEV51 [GenBank:KC802022] and IND/12/WB/JEV50 [GenBank:KC526871] and both of them were associated with mild JE in the patient 7 and 6 (Table 2). Since, the isolates IND/11/WB/JEV48, IND/11/WB/JEV49 and IND/12/WB/JEV51 were $100 \%$ identical with isolates IND/11/WB/JEV46 and IND/12/WB/JEV50, molecular 
Table 2 Short history of the patients from whom JEVs were isolated

\begin{tabular}{|c|c|c|c|c|c|c|c|c|c|c|}
\hline \multirow{2}{*}{$\begin{array}{l}\text { No. of } \\
\text { patients }\end{array}$} & \multirow{2}{*}{$\begin{array}{l}\text { Residence } \\
\text { Midnapore }\end{array}$} & \multirow{2}{*}{$\begin{array}{l}\text { JE vaccination } \\
\text { history } \\
\text { Yes }\end{array}$} & \multirow{2}{*}{$\begin{array}{l}\begin{array}{l}\text { Date of } \\
\text { onset }\end{array} \\
19 / 08 / \\
2011\end{array}$} & \multirow{2}{*}{$\begin{array}{l}\begin{array}{l}\text { Samples } \\
\text { collected } \\
\text { on }\end{array} \\
21 / 08 / \\
2011\end{array}$} & \multirow{2}{*}{$\begin{array}{l}\text { Sample } \\
\text { type }\end{array}$} & \multirow{2}{*}{$\begin{array}{l}\text { Clinical } \\
\text { outcome }\end{array}$} & \multicolumn{2}{|c|}{$\begin{array}{c}\text { Results of } \\
\text { ELISA (IgM) } \\
\text { RT-PCR }\end{array}$} & \multirow{2}{*}{$\begin{array}{l}\text { Isolates (GenBank } \\
\text { accession no.) } \\
\begin{array}{l}\text { IND/11/NB/JEV45 } \\
\text { (KC526872) }\end{array}\end{array}$} & \multirow{2}{*}{$\begin{array}{l}\text { Genotype } \\
\text { Genotype I }\end{array}$} \\
\hline & & & & & & & Negative & Positive & & \\
\hline Patient 2 & Midnapore & No & $\begin{array}{l}23 / 09 / \\
2011\end{array}$ & $\begin{array}{l}25 / 09 / \\
2011\end{array}$ & CSF & Severe & Negative & Positive & $\begin{array}{l}\text { IND/11/WB/JEV46 } \\
\text { (KC526869) }\end{array}$ & Genotype III \\
\hline Patient 3 & Hooghly & Unknown & $\begin{array}{l}27 / 09 / \\
2011\end{array}$ & $\begin{array}{l}28 / 09 / \\
2011\end{array}$ & CSF & Expired & Negative & Positive & $\begin{array}{l}\text { IND/11/WB/JEV47 } \\
\text { (KC526870) }\end{array}$ & Genotype III \\
\hline Patient 4 & $\begin{array}{l}\text { South } 24 \\
\text { Parganas }\end{array}$ & No & $\begin{array}{l}11 / 10 / \\
2011\end{array}$ & $\begin{array}{l}13 / 10 / \\
2011\end{array}$ & CSF & Severe & Negative & Positive & $\begin{array}{l}\text { IND/11/WB/JEV48 } \\
\text { (KC802020) }\end{array}$ & Genotype III \\
\hline Patient 5 & Howrah & No & $\begin{array}{l}\text { 20/08/ } \\
2011\end{array}$ & $\begin{array}{l}22 / 08 / \\
2011\end{array}$ & Serum & Severe & Negative & Positive & $\begin{array}{l}\text { IND/11/WB/JEV49 } \\
\text { (KC802021) }\end{array}$ & Genotype III \\
\hline Patient 6 & Malda & No & $\begin{array}{l}25 / 09 / \\
2012\end{array}$ & $\begin{array}{l}28 / 09 / \\
2012\end{array}$ & CSF & Mild & Negative & Positive & $\begin{array}{l}\text { IND/12/WB/JEV50 } \\
\text { (KC526871) }\end{array}$ & Genotype III \\
\hline Patient 7 & Birbhum & No & $\begin{array}{l}22 / 09 / \\
2012\end{array}$ & $\begin{array}{l}25 / 09 / \\
2012\end{array}$ & Serum & Mild & Negative & Positive & $\begin{array}{l}\text { IND/12/WB/JEV51 } \\
\text { (KC802022) }\end{array}$ & Genotype III \\
\hline
\end{tabular}

modelling and T-cell epitope prediction data of the isolates IND/11/WB/JEV48, IND/11/WB/JEV49 and IND/ $12 / \mathrm{WB} / J E V 51$ were not shown in Figure 2 and/or in Tables 3 and 4 respectively except the other isolates.

Among several nucleotide changes, some were nonsynonymous (data not shown) resulting in amino acid substitutions in JEV isolate-specific $\mathrm{E}$ protein in comparison with above said vaccine strain (Table 3 ). Moreover, the 8 amino acid substitutions (N2H, F107L, K138E, V176I, A177T, G244E, G261S and M279K) were common to all isolates whereas isolate-specific unique amino acid substitutions were also shown by a structure-based MSA of JEV isolates and SA14-14-2 vaccine strain [Additional file 2 (b)] which might confirm the alteration of $\mathrm{E}$ protein secondary structure with respect to disease severity.

\section{Molecular modelling of isolates-specific E protein}

Homology modelling of JEV isolates-specific 3-dimensional structures of $\mathrm{E}$ protein mapped with amino acid substitutions in relation to SA14-14-2 vaccine strain have been shown in Figure 2 (a)-(d). The amino acid substitutions were pointed out to areas with major secondary structures likely to affect the protein conformation regarding disease severity.

\section{T-cell epitope prediction}

Amino acid substitutions in E proteins of JEV isolates with potential T-cell epitopes were predicted in Table 4 and the substitutions in peptide-epitope sequences of the isolates with greater/lower IC50 values/scores were also given in Additional file 3 and Additional file 4 (actual Amino acid residues in peptide-epitope sequences of vaccine strain SA14-14-2 with IC50 values/scores were not shown). As a result, it is interesting to note that majority of the identified mutations falling within predicted T-cell peptide-epitopes might influence/alter immunogenicity/antigenicity in relation to said vaccine strain. While ranking the epitopes for mutation mapping, epitopes with calculated IC50 values/scores above 100 were not included since such peptide-epitopes were unlikely to yield significant immunogenicity.

\section{Discussion}

The virulence of JEV etiology is of grave public health concern in the state of WB. The present study reveals that $39 / 98$ (39.7\%) and 7/24 (29.1\%) samples were positive to JE by IgM-capture ELISA and RT-PCR method respectively. This observation proves that JE occurs recently and the ELISA negative acute samples with febrile illness for $\leq 3$ days should be subjected to RT-PCR test to confirm the total number of JE cases.

Pediatric-adolescents (71.7\%) were higher with JE cases than adults $(28.2 \%)$ as because pediatrics were infected possibly due to lack of immunity and adolescents were directly exposed to the mosquito vector (Culex sp.) bite, as they usually took active part in cultivation in water-logged crop fields where vectors usually breed. In contrast, low numbers of JE cases in adults were possibly due to the development of immunity by sub-clinical infections in natural time scale. In the present study, the maximum number of JE cases was found to occur in the monsoon period i.e. in the month of September when the Culex mosquitoes breed in the paddy fields covered with stagnant rain water.

However, we proposed that $52[(59-24)+(24-7)]$ samples with a history of 1-15 days' illness were true JE negative possibly due to either mishandling of samples which damaged the IgM antibody/the viral titre or the presence of another etiology responsible for AES. 


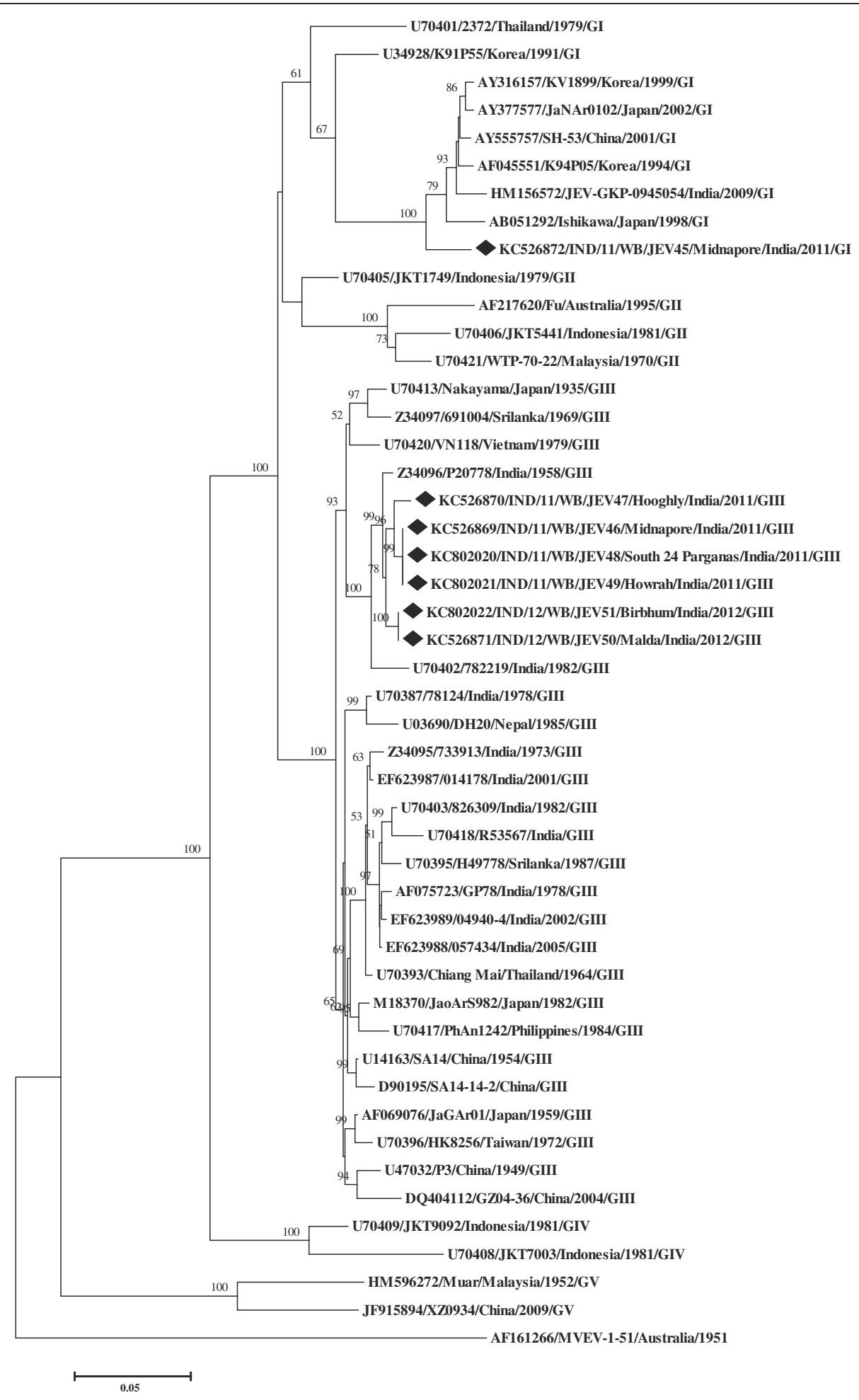

Figure 1 (See legend on next page.) 
(See figure on previous page.)

Figure 1 Phylogenetic relationship among JEV isolates from WB, India. The Neighbor-Joining (NJ) Phylogenetic tree, tested with Kimura 2-parameter model was generated by MEGA5, using the complete E gene nucleotide sequences of $4 \mathrm{JEV}$ isolates from hospitalized AES case-patients in West Bengal during 2011-12, with reference to other 40 wild type JEV strains from worldwide. The strain MVEV-1-51 was used as an out group for generating the rooted tree. The $\geq 50 \%$ bootstrap support values (1000 pseudo replicates) were shown in corresponding nodes. Horizontal branch lengths are proportional to genetic distance and vertical branch lengths have no significance. Each taxon is named systematically by mentioning the accession number, strain/ isolate name, country of origin, year of isolation and genotype. The isolates' sequences used in this study were indicated by ' mark. Scale bar indicates nucleotide substitutions per site.

In molecular phylogeny, JEV GIII isolates i.e. IND/11/ WB/JEV46 [GenBank:KC526869], IND/11/WB/JEV47 [GenBank:KC526870], IND/11/WB/JEV48 [GenBank: KC802020], IND/11/WB/JEV49 [GenBank:KC802021], IND/12/WB/JEV50 [GenBank:KC526871] and IND/12/ WB/JEV51 [GenBank:KC802022] showed closer clustering, even though all of 6 isolates were from a geographically distant location or different districts of the state (Table 2, Figure 1). This indicated similarities among the isolates circulating in the 2 consecutive years 2011, 2012. Moreover, based on the present study, we stated that there had been simultaneous circulation of both JEV GI [GenBank:KC526872] and GIII [GenBank: KC526869] in the district of Midnapore, WB in 2011 corroborating with our earlier findings [21]. It would be interesting to determine whether GI has become the predominant genotype or co-circulate with GIII in WB, India; additional JEV isolates from human clinical samples will be required to confirm the findings. Our study also reveals that the JEV GI [GenBank:KC526872] was isolated from a 9-year old boy-patient who had already been immunized with live attenuated JE vaccine derived from GIII strain SA14-14-2 and the boy was found to have clinically developed moderate JE with high fever including unconsciousness, neck rigidity and convulsion. In this connection, the efficacy of the vaccine to protect against GI isolate of JEV needs careful evaluation. In addition, we have identified the samples from 3 adult patients (average age of 47 years) with AES belonging to district Hooghly, WB were subjected to tissue culture for JEV isolation (Table 1) and out of these 3 samples, only 1 was confirmed as JE positive by RT-PCR (Table 2). This observation suggested that adults in this district were at higher risk for JE. Therefore, the state health department, government of WB should take initiative about JE vaccination to this population to overcome the disease burden.

The 500 amino acids long JEV E protein is encoded by $E$ gene of 1500 nucleotides in length. The $E$ protein of flaviviruses, including JEV, plays an important role in immunogenicity, tissue tropism, cell fusion and infection, and virus maturation [30]. The predicted 3-dimensional structures of isolate-specific $\mathrm{E}$ protein were modelled onto the crystal structure of JEV SA14-14-2 vaccine
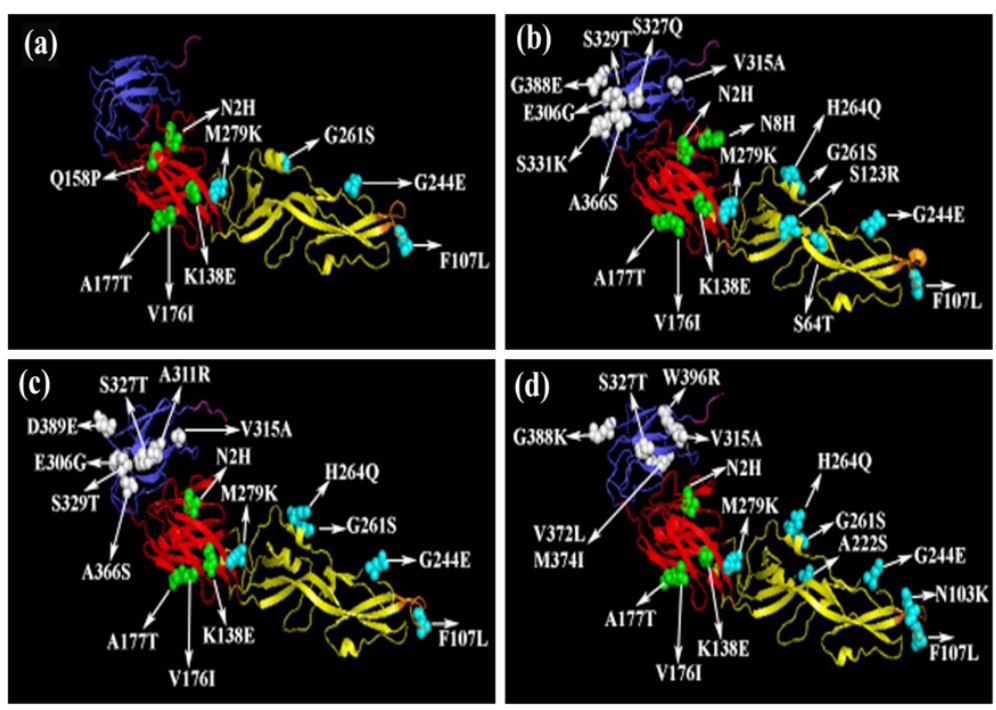

Figure 2 Structural locations of JEV isolate-specific amino acid variations in E protein. Predicted 3-dimensional structures of JEV isolatesspecific E protein [2 (a) - 2 (d) for IND/12/WB/JEV50, IND/11/WB/JEV47, IND/11/WB/JEV46 and IND/11/WB/JEV45 respectively] derived from the crystal structure of E protein of JEV SA14-14-2 vaccine strain, showing amino acid substitutions in different domains i.e. domain I (red), domain II including orange colored fusion loop (yellow) and domain III (blue) as designated in earlier studies [32,33]. 
Table 3 Comparison of E protein based amino acid substitutions identified in WB isolates with respect to wild type SA14-14-2 vaccine stain of JEV

\begin{tabular}{|c|c|c|c|c|c|c|c|c|}
\hline \multirow{2}{*}{$\begin{array}{l}\text { SI. } \\
\text { no. }\end{array}$} & \multirow{2}{*}{$\begin{array}{l}\text { Identified E } \\
\text { protein } \\
\text { domains }\end{array}$} & \multirow{2}{*}{$\begin{array}{l}\text { Positions } \\
\text { wise amino } \\
\text { acid } \\
\text { substitutions }\end{array}$} & \multirow{2}{*}{$\begin{array}{l}\text { Types of } \\
\text { amino acid } \\
\text { substitutions }^{a}\end{array}$} & \multirow{2}{*}{$\begin{array}{l}\text { Wild type vaccine } \\
\text { strain } \\
\text { SA14-14-2 }\end{array}$} & \multicolumn{4}{|c|}{ WB Isolates } \\
\hline & & & & & $\begin{array}{l}\text { IND/12/WB/ } \\
\text { JEV50 }\end{array}$ & $\begin{array}{l}\text { IND/11/WB/ } \\
\text { JEV47 }\end{array}$ & $\begin{array}{l}\text { IND/11/WB/ } \\
\text { JEV46 }\end{array}$ & $\begin{array}{l}\text { IND/11/WB/ } \\
\text { JEV45 }\end{array}$ \\
\hline 1 & Domain I & $\mathrm{N} 2 \mathrm{H}$ & NC & $\mathrm{N}$ & $\mathrm{H}$ & $\mathrm{H}$ & $\mathrm{H}$ & $\mathrm{H}$ \\
\hline 2 & Domain I & $\mathrm{N} 8 \mathrm{H}$ & NC & $N$ & . & $\mathrm{H}$ & . & \\
\hline 3 & Domain I & K138E & NC & K & $E$ & $E$ & E & E \\
\hline 4 & Domain I & Q158P & C & Q & $P$ & . & . & \\
\hline 5 & Domain I & V176I & $C$ & V & । & I & I & I \\
\hline 6 & Domain I & $\mathrm{A} 177 \mathrm{~T}$ & NC & A & $\mathrm{T}$ & T & T & $\mathrm{T}$ \\
\hline 7 & Domain II & S64T & $C$ & S & & T & & . \\
\hline 8 & Domain II & N103K & NC & $\mathrm{N}$ & . & . & . & K \\
\hline 9 & Domain II & F107L & NC & F & $L$ & L & L & L \\
\hline 10 & Domain II & S123R & NC & S & . & R & . & \\
\hline 11 & Domain II & A222S & $\mathrm{NC}$ & A & . & . & . & S \\
\hline 12 & Domain II & G244E & NC & G & E & $E$ & E & $E$ \\
\hline 13 & Domain ॥ & G261S & NC & G & S & $S$ & S & S \\
\hline 14 & Domain ॥ & $\mathrm{H} 264 \mathrm{Q}$ & $\mathrm{NC}$ & $\mathrm{H}$ & & Q & Q & Q \\
\hline 15 & Domain II & M279K & NC & M & K & K & K & K \\
\hline 16 & Domain III & E306G & NC & $E$ & & G & G & . \\
\hline 17 & Domain III & $A 311 R$ & NC & A & . & . & R & \\
\hline 18 & Domain III & V315A & C & V & & A & A & $A$ \\
\hline 19 & Domain III & $\mathrm{S} 327 \mathrm{Q} / \mathrm{T}$ & C & S & . & Q & T & $\mathrm{T}$ \\
\hline 20 & Domain III & S329T & $C$ & S & . & T & T & . \\
\hline 21 & Domain III & S331K & NC & S & . & K & . & \\
\hline 22 & Domain III & A366S & NC & A & . & $S$ & S & \\
\hline 23 & Domain III & V372L & C & V & . & . & . & L \\
\hline 24 & Domain III & M374I & C & M & . & . & . & । \\
\hline 25 & Domain III & G388E & NC & G & . & $\mathrm{E}$ & . & K \\
\hline 26 & Domain III & D389E & $C$ & $\mathrm{D}$ & . & . & E & \\
\hline 27 & Domain III & W396R & NC & W & & & & $\mathrm{R}$ \\
\hline 28 & Stem & R416K & C & R & K & K & . & \\
\hline 29 & Stem & G432R & NC & G & . & $\mathrm{R}$ & . & \\
\hline 30 & Stem & R439K & C & R & . & K & K & K \\
\hline 31 & Transmembrane & L463R & NC & L & & & $\mathrm{R}$ & . \\
\hline 32 & Transmembrane & L467E & $\mathrm{NC}$ & L & . & E & . & \\
\hline 33 & Transmembrane & A481D & NC & A & . & D & . & \\
\hline
\end{tabular}

Different amino acid substitutional positions were categorized into domains based on earlier reports [32,33].

Identical amino acids in WB isolates with respect to wild type SA14-14-2 vaccine stain of JEV were indicated by ".".

${ }^{a}$ Amino acid substitutions were designated as C for conservative and NC for non-conservative.

strain E protein [31] and composed of separate structural domains [designated as domain I (DI), domain II (DII) and domain III (DIII)] including stem (ST) and transmembrane (TM) region like other flaviviruses $[32,33]$. DI, which is referred to as the central domain, consists of 127 residues (1-51, 135-193 and 283-299);
DII, which is called as dimerization domain, consists of 172 residues (52-134 and 194-282); the most antigenic part of E protein is DIII, a continuous stretch of 100 residues (300-399) that has been implicated in receptor binding; a stretch of 52 residues (400-451) is considered as ST region of E protein not simply to support the 
Table 4 Identification of E protein based amino acid substitutions in JEV WB isolates with potential T-cell epitopes

\begin{tabular}{|c|c|c|c|c|c|c|c|}
\hline \multirow{2}{*}{$\begin{array}{l}\text { SI. } \\
\text { no. }\end{array}$} & \multirow{2}{*}{$\begin{array}{l}\text { Identified E } \\
\text { protein } \\
\text { domains }\end{array}$} & \multirow{2}{*}{$\begin{array}{l}\text { Amino acid } \\
\text { substitutions } \\
\text { with } \\
\text { positions }\end{array}$} & \multirow[t]{2}{*}{ Associated HLA alleles" } & \multicolumn{4}{|c|}{ WB Isolates with amino acid substitutions } \\
\hline & & & & $\begin{array}{l}\text { IND/12/WB/ } \\
\text { JEV50 }\end{array}$ & $\begin{array}{l}\text { IND/11/WB/ } \\
\text { JEV47 }\end{array}$ & $\begin{array}{l}\text { IND/11/WB/ } \\
\text { JEV46 }\end{array}$ & $\begin{array}{l}\text { IND/11/WB/ } \\
\text { JEV45 }\end{array}$ \\
\hline 1 & Domain I & $\mathrm{N} 2 \mathrm{H}$ & - & Y & Y & Y & Y \\
\hline 2 & Domain I & $\mathrm{N} 8 \mathrm{H}$ & - & - & Y & - & - \\
\hline 3 & Domain I & $\mathrm{K} 138 \mathrm{E}$ & $\mathrm{HLA}-\mathrm{A}^{*} 24$ & Y & Y & Y & Y \\
\hline 4 & Domain I & Q158P & HLA-A*1101, HLA-A*24 & Y & - & - & - \\
\hline \multirow[t]{3}{*}{5} & Domain I & V176l & HLA-A*0101, HLA-A*0301, & Y & Y & Y & Y \\
\hline & & & HLA-A*1101, HLA-A*6801, & & & & \\
\hline & & & HLA-A*6802, HLA-B*07, HLA-B*51 & & & & \\
\hline \multirow[t]{3}{*}{6} & Domain I & A177T & HLA-A*0101, HLA-A*0301, & Y & Y & Y & Y \\
\hline & & & HLA-A*1101, HLA-A*6801, & & & & \\
\hline & & & $\mathrm{HLA}-\mathrm{B}^{*} 07, \mathrm{HLA}-\mathrm{B}^{*} 51$ & & & & \\
\hline \multirow[t]{3}{*}{7} & Domain II & S64T & HLA-A*0202, HLA-A*0203, & - & Y & - & - \\
\hline & & & HLA-A*0206, HLA-A*1101, & & & & \\
\hline & & & HLA-A*24, HLA-A*6802,HLA-B*27 & & & & \\
\hline 8 & Domain II & N103K & $\mathrm{HLA}-\mathrm{A}^{*} 24$ & - & - & - & Y \\
\hline 9 & Domain ॥ & F107L & HLA-A*1101, HLA-A*24, HLA-B*51 & Y & Y & Y & Y \\
\hline \multirow[t]{2}{*}{10} & Domain ॥ & S123R & HLA-A*0301, HLA-A*1101, & - & Y & - & - \\
\hline & & & HLA-A*24, HLA-A*6801, HLA-B*27 & & & & \\
\hline 11 & Domain ॥ & $\mathrm{A} 222 \mathrm{~S}$ & $\mathrm{HLA}-\mathrm{B}^{*} 40, \mathrm{HLA}-\mathrm{B}^{*} 44$ & - & - & - & Y \\
\hline \multirow[t]{2}{*}{12} & Domain II & G244E & HLA-A*0101, HLA-A*0201, & Y & Y & Y & Y \\
\hline & & & HLA-A*0301 & & & & \\
\hline 13 & Domain II & G261S & - & Y & Y & Y & Y \\
\hline 14 & Domain II & $\mathrm{H} 264 \mathrm{Q}$ & HLA-A*0202, HLA-A*0206, HLA-B*51 & - & Y & Y & Y \\
\hline \multirow[t]{3}{*}{15} & Domain ॥ & M279K & HLA-A*0301, HLA-A*1101, & Y & Y & Y & Y \\
\hline & & & HLA-A*24, HLA-A*6802, HLA-B*07, HLA- & & & & \\
\hline & & & $\mathrm{B}^{*} 40, \mathrm{HLA}-\mathrm{B}^{*} 44$ & & & & \\
\hline 16 & Domain III & E306G & HLA-A*0301, HLA-A*1101, HLA-A*24 & - & Y & Y & - \\
\hline 17 & Domain III & $A 311 R$ & HLA-A*0301, HLA-A*1101, HLA-B*27 & - & - & Y & - \\
\hline 18 & Domain III & V315A & - & - & Y & Y & Y \\
\hline \multirow[t]{4}{*}{19} & Domain III & S327Q & HLA-A*0101, HLA-A*0301, & - & Y & - & - \\
\hline & & & HLA-A*1101, HLA-A*24 & & & & \\
\hline & & S327T & HLA-A*0101, HLA-A*0301, & - & - & Y & Y \\
\hline & & & HLA-A*1101, HLA-A*24 & & & & \\
\hline \multirow[t]{2}{*}{20} & Domain III & S329T & HLA-A*0301, HLA-A*1101, & - & Y & Y & - \\
\hline & & & HLA-A*24, HLA-B*51 & & & & \\
\hline \multirow[t]{2}{*}{21} & Domain III & S331K & HLA-A*0301, HLA-A*1101, & - & Y & - & - \\
\hline & & & $\mathrm{HLA}-\mathrm{A}^{*} 24, \mathrm{HLA}-\mathrm{B}^{*} 51$ & & & & \\
\hline \multirow[t]{4}{*}{22} & Domain III & A366S & HLA-A*0101, HLA-A*0201, & - & Y & Y & - \\
\hline & & & HLA-A*0202, HLA-A*0206, & & & & \\
\hline & & & HLA-A*0301, HLA-A*1101, & & & & \\
\hline & & & $\mathrm{HLA}-\mathrm{B}^{*} 40, \mathrm{HLA}-\mathrm{B}^{*} 44$ & & & & \\
\hline 23 & Domain III & V372L & - & - & - & - & Y \\
\hline 24 & Domain III & M374I & - & - & - & - & Y \\
\hline
\end{tabular}




\section{Table 4 Identification of E protein based amino acid substitutions in JEV WB isolates with potential T-cell epitopes} (Continued)

\begin{tabular}{|c|c|c|c|c|c|c|c|}
\hline \multirow[t]{4}{*}{25} & \multirow[t]{4}{*}{ Domain III } & \multirow[t]{2}{*}{ G388E } & HLA-A*0301, HLA-A*6802, & \multirow[t]{2}{*}{-} & \multirow[t]{2}{*}{ Y } & \multirow[t]{2}{*}{-} & \multirow[t]{2}{*}{-} \\
\hline & & & $\mathrm{HLA}-\mathrm{B}^{*} 27$ & & & & \\
\hline & & \multirow[t]{2}{*}{ G388K } & HLA-A*0301, HLA-A*1101, & \multirow[t]{2}{*}{-} & \multirow[t]{2}{*}{-} & \multirow[t]{2}{*}{-} & \multirow[t]{2}{*}{ Y } \\
\hline & & & HLA-A*6802, HLA-B*07, HLA-B*27 & & & & \\
\hline 26 & Domain III & D389E & $\begin{array}{l}\text { HLA-A*0301, HLA-A*1101, HLA-A*6802, HLA-B } \\
{ }^{*} 27, \mathrm{HLA}^{*} \mathrm{~B}^{*} 40, \mathrm{HLA}-\mathrm{B}^{*} 44\end{array}$ & - & - & Y & - \\
\hline 27 & Domain III & W396R & - & - & - & - & Y \\
\hline 28 & Stem & R416K & - & Y & Y & - & - \\
\hline 29 & Stem & G432R & - & - & Y & - & - \\
\hline 30 & Stem & R439K & - & - & Y & Y & Y \\
\hline 31 & Transmembrane & L463R & - & - & - & Y & - \\
\hline 32 & Transmembrane & L467E & - & - & Y & - & - \\
\hline 33 & Transmembrane & A481D & - & - & $Y$ & - & - \\
\hline
\end{tabular}

protein, but rather, it plays a key role in viral entry and maintenance of the protein complexes on the virion surface followed by TM, a 49 residues (452-500) long region playing a major role in the processing, sub-cellular localization and assembly of $E$ protein [Additional file 2 (a)].

In the present study, in order to identify the possible correlation of clinical severity (i.e. neurovirulence/ neuroinvasiveness) and altered immunogenicity of JEV infection in WB with isolate-specific amino acid changes of $\mathrm{E}$ protein, we analyzed $\mathrm{E}$ protein amino acid changes of the viral isolates with respect to SA14-14-2 vaccine strain. Our study showed greater amino acid changes in the JEV isolates circulating in WB than that of SA14-142 (Table 3). It was found that 8 critical amino acid changes at E107 $(\mathrm{F} \rightarrow \mathrm{L}), \mathrm{E} 138(\mathrm{~K} \rightarrow \mathrm{E}), \mathrm{E} 176(\mathrm{~V} \rightarrow \mathrm{I}), \mathrm{E} 177$ $(\mathrm{A} \rightarrow \mathrm{T})$, E264 $(\mathrm{H} \rightarrow \mathrm{Q})$, E279 $(\mathrm{M} \rightarrow \mathrm{K})$, E315 $(\mathrm{V} \rightarrow \mathrm{A})$ and E439 $(\mathrm{R} \rightarrow \mathrm{K})$ (Table 3$)$ of 3 isolates i.e. IND/11/WB/ JEV45-IND/11/WB/JEV47 (except the isolate IND/12/ WB/JEV50) display neurovirulence in the patient 1-3 respectively (Table 2). That type of severity due to JEV infection worldwide or in earlier reports [14,34-37] has been linked to the amino acid alterations in the virus. Moreover, the above said eight critical amino acid changes including E123 $(\mathrm{S} \rightarrow \mathrm{R})$ and E306 $(\mathrm{E} \rightarrow \mathrm{G})$ in the isolate IND/11/WB/JEV47 and only E306 $(\mathrm{E} \rightarrow \mathrm{G})$ in the isolate IND/11/WB/JEV46 (Table 3) might introduce much more neurovirulence/neuroinvasiveness corroborating with previous findings $[38,39]$ and the increased virulence of the isolates is likely to cause death and severe JE/AES in the patient 3 and 2 respectively (Table 2 ). In contrast, although the isolate IND/12/WB/JEV50 showed critical amino acid changes, it did not include $\mathrm{H} \rightarrow \mathrm{Q}$ at $\mathrm{E} 264, \mathrm{~V} \rightarrow \mathrm{A}$ at $\mathrm{E} 315$ and $\mathrm{R} \rightarrow \mathrm{K}$ at E439 which were found to be closely associated with neurovirulence (Table 3). Therefore, it might result in low neurovirulence in the patient 4 who developed mild JE/AES (Table 2). Moreover, regarding the low neurovirulence property of the isolate IND/12/WB/JEV50, it was speculated that a novel conservative amino acid substitution i.e. Q158P was mapped onto an $\alpha$-helix of glycosylated $\mathrm{E}_{0} \mathrm{~F}_{0}$ loop $[31,40]$ in DI of that isolate's E protein [Figure 2 (a)] and was found to have potential to break (as because the proline is a helix breaker) the secondary structural elements surrounding that position and might also affect the $\mathrm{N}^{154}$ glycosylation site [41] of $\mathrm{E}$ protein of the isolate [Additional file 2 (b)], being less severe for the patient 4 .

The crystal structure of E protein of WNV, a Flavivirus closely related to JEV [42], illustrated that the finger like projection of a stretch of 13 residues (98-110) long fusion loop (FL) is also present in the DII of JEV E protein, essential for viral infectivity, membrane fusion and is recognized as neutralizing epitope [31,43]. In the study, Hopp and Woods hydrophilicity prediction [44] revealed that the non-conservative substitution of basic lysine (K) for polar asparagine $(\mathrm{N})$ resulted in decreased (IC50 value/score) hydrophilicity of ${ }^{98}$ DRGWGKGCGLFKG ${ }^{110}$ peptide sequence of the isolate IND/11/WB/JEV45 E protein [Table 4, Additional file 2(b) and Additional file 3]. This in turn, indicates altered antigenicity of the isolate in comparison with SA14-14-2 vaccine strain. Moreover, we found that another non-conservative amino acid change i.e. E107 $(\mathrm{F} \rightarrow \mathrm{L})$ at the tip of FL region of $\mathrm{E}$ protein of all JEV isolates circulating in WB might lead to escape from antibody neutralization or neutralizing epitope with decreased/increased IC50 value/score in relation to said vaccine strain [Table 4, Additional file 2(b), Additional file 3 and Additional file 4]. This finding was supported by previous studies $[31,45]$. 
It is noteworthy that the amino acid substitutions at E64 $(\mathrm{S} \rightarrow \mathrm{T})$, E244 $(\mathrm{G} \rightarrow \mathrm{E}), \mathrm{E} 306(\mathrm{E} \rightarrow \mathrm{G})$ and E311 $(\mathrm{A} \rightarrow \mathrm{R})$ in the DII and DIII of JEV isolate-specific $E$ protein with respect to said vaccine strain [Table 4, Additional file 2 (b), Additional file 3 and Additional file 4] might largely change immunogenicity (with decreased/increased IC50 value/score) of the isolates corroborating with earlier reports [33,40,46-49]. According to earlier workers $[32,40,50]$, the surface exposed BC loop (E229-E333), DE loop (E365-368) and the putative receptor binding RGD motif (E387-E389), adjacent to FG loop (E389-E391) region were recognized as most antigenic part of DIII region of WNV E protein (closely related to JEV). In the present study, some amino acid substitutions (i.e. S327Q/T, S329T, S331K, A366S, G388E/K and D389E) were observed within and/or adjacent to BC loop, DE loop and RGD associated FG loop region of the JEV isolates' (IND/11/WB/JEV45-IND/11/WB/JEV47) E protein (Table 3). In Hopp and Woods hydrophilicity prediction [44], both conservative and non-conservative substitutions of S327Q/T, S329T, S331K (polar to charged), A366S (non-polar to polar) and G388E/K (non-polar to charged) resulting in increased hydrophilicity of the ${ }^{327}$ QYTGKDG $^{333}$ / ${ }^{327}$ TYTGSDG $^{333}$ / ${ }^{327}$ TYSGSDG $^{333}$, ${ }^{365} \mathrm{SSNV}^{368}$ and ${ }^{387} \mathrm{REDKQ}^{391}$ / ${ }^{387} \mathrm{RKDKQ}^{391}$ peptide sequences of above mentioned JEV isolates in relation to SA14-14-2 vaccine strain might lead to escape from antibody neutralization or neutralizing epitope due to increased/decreased IC50 value/score [Table 4, Additional file 2(b), Additional file 3 and Additional file 4] whereas another conservative amino acid change at E389 $(\mathrm{D} \rightarrow \mathrm{E})$ in the $\mathrm{BC}$ loop region of $\mathrm{E}$ protein of the isolate IND/ $11 / \mathrm{WB} / \mathrm{JEV} 45$ retained the same hydrophilicity of the ${ }^{387}$ RGEKQ $^{391}$ peptide sequence in comparison with said vaccine strain.

Several mutations in the structural E protein gene region were seen to fall within the predicted T-cell epitopes (Table 4) as a result of analysis of the changes that might affect the immunogenicity of these isolates. Involvement of epitopes presented by major HLA alleles, such as HLA-A*02 and HLA-A*11 were shown by the present study. Moreover, HLA-A*11, one of the main HLA types, is found to be present in population across the world particularly with its high prevalence in South East Asia [51]. When the variations in these epitopes take place, they may have the potential to affect the cellmediated immune response against JEV infection.

It is worthy to mention that substitutions of non-polar to charged amino acid residues at E432 $(\mathrm{G} \rightarrow \mathrm{R}), \mathrm{E} 463$ $(\mathrm{L} \rightarrow \mathrm{R}), \mathrm{E} 467(\mathrm{~L} \rightarrow \mathrm{E})$ and $\mathrm{E} 481(\mathrm{~A} \rightarrow \mathrm{D})$ in the isolatespecific ST and TM region of E protein (Table 3) might facilitate the processing, sub-cellular localization and assembly of E protein of the isolates, which was proved by earlier study [52]. Interestingly, the present JEV GI isolate
IND/11/WB/JEV45 had a non-conservative amino acid substitution at E222 $(\mathrm{A} \rightarrow \mathrm{S})$ corresponding to DII region of its E protein [Table 3, Figure 2 (d), Additional file 2 (b)] which was also observed in the previous study [53]. Such type of mutation might influence/facilitate vector competency and viral infectivity. This was similar to the recent findings [54]. All WB isolates showed amino acid mutations at E2 (Asn to His) and E261 (Gly to Ser) and the isolate-specific mutations i.e. $\mathrm{N} 8 \mathrm{H}$ of IND/11/WB/JEV47; R416K of IND/11/WB/JEV47 and IND/12/WB/JEV50 and V372L, M374I and W396R of IND/11/WB/JEV45 were also observed in the study (Table 3), but the biological significance of those mutations were unknown.

\section{Conclusions}

In summary, our study reveals that JEV GI and GIII cocirculate with genetic changes in the state of $\mathrm{WB}$, India during 2011-12. The JEV GI isolate IND/11/WB/JEV45 [GenBank:KC526872] from a 9-year old boy-patient who had been vaccinated with the live attenuated JE vaccine derived from JEV GIII SA14-14-2 strain but developed moderate JE/AES as because the GI isolate differed from the JEV GIII vaccine strain by means of some amino acid substitutions which were responsible for both neurovirulence and alteration of immunogenicity/antigenicity. Therefore, the vaccine efficacy to protect against JEV GI may demand careful evaluation. However, using a bioinformatics approach we point out that this study is a localized example of molecular evolution of $\mathrm{E}$ protein gene of JEV isolates in nature, which is likely to affect the disease profile. Further, functional studies on these mutant isolates would help us to understand the correlation of the genetic changes with respect to JEV virulence and pathogenesis.

\section{Ethical approval}

The study was duly approved by the joint ethical committee of ICMR (Indian Council of Medical Research) virus unit and NICED (National Institute of Cholera and Enteric Diseases), Kolkata, India.

\section{Additional files}

Additional file 1: Sources of the JEV strains/isolates used in the phylogenetic analysis in this study. All strains/isolates are JEV, except Murray Valley encephalitis virus strain (MVE-1-51) used as an out group for phylogenetic analysis in this study. ${ }^{* * *}$ Isolates were $100 \%$ identical with each other.

Additional file 2: (a) Schematic structural representation of $E$ protein of JEV isolates. Here, DI, DII (FL), DIII, ST and TM were symbolized for domain I (red), domain II with orange colored fusion loop (yellow), domain III (blue), stem (magenta) and transmembrane (gray) region respectively including the span/stretch of respective domain/ region with above shown numbering, according to previous reports [32, 33]. (b) A comparison of structure-based multiple sequence alignment of 
JEV isolates-specific E protein with respect to SA14-14-2 vaccine strain Domains/regions were colored as Figure 2 (a). Secondary structural elements (described in terms of E-extended strand/ $\beta$-sheet, $\mathrm{H}$ - $\alpha$-helix and C-coil/turn/bend) were shown below each sequence alignment. Underlined bold faces amino acids represent the JEV isolates-specific amino acid substitutions in E protein. Amino acid substitutions leading to escape from antibody neutralization or neutralizing epitopes or related to neuorovirulence/neuroinvasiveness or both found in the JEV isolates with respect to SA14-14-2 vaccine strain were represented by shaded dot, dot and bold asterisk $\left(^{*}\right)$ respectively. One amino acid substitution at E158 $(\mathrm{Q} \rightarrow \mathrm{P})$ in the isolate IND/12/WB/JEV50 resulting in secondary structural changes marked as green shaded bold faces.

Additional file 3: Amino acid substitutions in E protein epitopes of JEV WB isolates associated with HLA-A alleles as predicted by EpiJen serve. The values given within the bracket indicates the 50\% inhibitory concentration (IC50) of the peptide, a measure of the binding affinity. An IC50 value $<50$ is considered as a good affinity. Amino acid substitutions in the predicted epitopes of E protein are marked as bold.

Additional file 4: Amino acid substitutions in $E$ protein epitopes of JEV WB isolates associated with HLA-B alleles as predicted by EpiJen server. The values given within the bracket indicates the 50\% inhibitory concentration (IC50) of the peptide, a measure of the binding affinity. An IC50 value $<50$ is considered as a good affinity. Amino acid substitutions in the predicted epitopes of E protein are marked as bold.

\section{Competing interests}

The authors declare that they have no competing interests.

\section{Authors' contributions}

AS conceived the study, the design, and drafted the manuscript. AS carried out serology and molecular work. AS, AB, BKP participated in immunoinformatics analysis. AS, AB, BKP, SKM and SC contributed to the data analysis and data interpretation. All authors read and approved the final manuscript.

\section{Acknowledgements}

This work was supported by the grant from The Department of Science and Technology (DST), Government of West Bengal, India [No. 396(Sanc.)/ST/P/ S\&T/9G-27/2007]. The authors are indebted to Dr. Sekhar Chakrabarti, the Officer-In-Charge, ICMR Virus Unit, for allowing them to carry out the work. We also gratefully acknowledge the help we received from NIV, Pune for providing us with the ELISA kit for the detection of IgM antibody to Japanese encephalitis virus. The enthusiastic help obtained from the physicians of the district hospitals, for providing us the samples from clinically suspected JE/AES for this study, is gratefully acknowledged.

\section{Author details}

'ICMR virus unit, GB- 4, 1st Floor, ID \& BG Hospital, 57, Dr. S. C. Banerjee Road, Beliaghata, Kolkata 700010, West Bengal, India. ${ }^{2}$ Department of Microbiology, The University of Burdwan, Golapbag, Burdwan, West Bengal, India. ${ }^{3}$ Department of Biotechnology, St. Xavier's College, Kolkata, West Bengal, India.

Received: 22 March 2013 Accepted: 30 July 2013

Published: 8 August 2013

\section{References}

1. Lindenbach $B D$, Thiel HJ, Rice CM: Flaviviridae: the viruses and their replication. In Fields virology. Volume 1. 4th edition. Edited by Knipe DM, Howley PM. Philadelphia, PA: Lippincott Williams \& Wilkins; 2007:1101-1152.

2. Mackenzie JS, Gubler DJ, Petersen LR: Emerging flaviviruses: the spread and resurgence of Japanese encephalitis, West Nile and dengue viruses. Nat Med 2004, 10(suppl 12):S98-S109.

3. Tanaka M, Aira Y, Igarashi A: Comparative nucleotide and amino acid sequences of five Japanese encephalitis virus strains isolated in Japan and China. Trop Med 1991, 33:15-21.

4. World Health Organization: Japanese encephalitis vaccines-WHO position paper. Wkly Epidemiol Rec 2006, 81:331-340.

5. Geevarghese G, Kanogia PC, Mishra AC: Japanese encephalitis-Vector Biology. NIV Pune Year Book, Himayatnagar: Orient Longman Publication; 2004.
6. The Center for Food Security and Public Health, lowa State University: Japanese Encephalitis: Japanese B Encephalitis, Arbovirus B, Mosquito-borne Encephalitis Virus. http://www.cfsph.iastate.edu/Factsheets/pdfs/ japanese_encephalitis.pdf.

7. Reuben R, Gajanana A: Japanese encephalitis in India. Indian J Pediatr 1997, 64:243-251.

8. Diagana M, Preux PM, Dumas M: Japanese encephalitis revisited. J Neurol Sci 2007, 262:165-170.

9. Chambers TJ, Hahn CS, Galler R, Rice CM: Flavivirus genome organisation, expression and replication. Annu Rev Microbio 1990, 44:649-688.

10. Fields BN, Knipe DM, Howley PM: Fields Virology. Philadelphia, PA: Lippincott Williams \& Wilkins; 2007.

11. Sumiyoshi H, Mori C, Fuke I, Morita K, Kuhara S, Kondou J, Kikuchi Y, Nagamtu $H$, Igarashi A: Complete nucleotide sequence of the Japanese encephalitis virus genome RNA. Virology 1987, 161:497-510.

12. Monath TP: Flaviviruses. In Virology. Edited by Fields BN. New York: Raven Press; 1990:763-814.

13. Rice CM, Strauss EG, Strauss JH: Structure of the Flavivirus genome. In The Togaviridae and Flaviviridae. Edited by Schlesinger S, Schlesinger MJ. New York: Plenum Press; 1986:279-326.

14. McMinn PC: The molecular basis of virulence of the encephalitogenic flaviviruses. J Gen Virol 1997, 78:2711-2722.

15. Solomon T, Ni H, Beasley DW, Ekkelenkamp M, Cardosa MJ, Barrett AD: Origin and evolution of Japanese encephalitis virus in Southeast Asia. J Virol 2003, 77:3091-3098.

16. Fulmali PV, Sapkal GN, Athawale S, Gore MM, Mishra AC, Bondre VP: Introduction of Japanese encephalitis virus genotype I, India. Emerg Infect Dis 2011, 17:319-321.

17. Smithburn KC, Kerr JA, Gatne PB: Neutralising antibodies against certain viruses in the sera of residents of India. J Immunol 1954, 72:248-251.

18. Namachivayam V, Umayal K: Japanese Encephalitis, Proceedings of National Conference. New Delhi: Indian Council of Medical Research; 1982:30-33.

19. Dhillon GP, Raina VK: Epidemiology of Japanese encephalitis in context with Indian scenario. Indian J Med Assoc 2008, 106:660-663.

20. Kabilan L, Rajendran R, Arunachalam N, Ramesh S, Srinivasan S, Samuel PP, Dash AP: Japanese encephalitis in India: an overview. Indian J Pediatr 2004, 71:609-615.

21. Sarkar A, Taraphdar D, Mukhopadhyay SK, Chakrabarti S, Chatterjee S: Molecular evidence for the occurrence of Japanese encephalitis virus genotype I and III infection associated with acute encephalitis in patients of West Bengal, India, 2010. Virol J 2012, 9:271.

22. Sarkar A, Taraphdar D, Mukhopadhyay BB, Kumar M, Mukhopadhyay SK, Chatterjee S: Influence of socio-economic status and environmental factors on serologically diagnosed Japanese encephalitis cases in the state of West Bengal, India during 2005-2010. Health 2012, 4:6-12.

23. Ghosh SN, Rodrigues FM, Seth GP, Tongaonkar SS, Padbidri VS, Gupta NP: Investigations on the outbreak of Japanese encephalitis in Burdwan district, West Bengal. Part II. Serological survey of human population. Indian J Med Res 1975, 63:1472-1477.

24. Rodrigues FM, Ghosh SN, Banerjee K, Chatterjee AK, Gupta NP: A postepidemic serological survey of humans in Bankura district, West Bengal, following the epidemic of Japanese encephalitis in 1973. Indian J Med Res 1975, 63:1478-1485.

25. Rajagopalan PK, Panicker KN: A note on the 1976 epidemic of Japanese encephalitis in Burdwan district West Bengal. Indian J Med Res 1978, 68:3938.

26. Banerjee K, Sengupta SN, Dandawate CN, Tongaonkar SS, Gupta NP: Virological and serological investigations of an epidemic of encephalitis which occurred at Bankura district, West Bengal. Indian J Med Res 1976, 64:121-130.

27. Mukhopadhyay BB, Mukherjee B, Bagchi SB, Chakraborty M, Mukherjee KK: An epidemiological investigation of Japanese encephalitis outbreak in Burdwan, District of west Bengal during 1987-1988. Indian J Public Health 1990, 34:107-116.

28. Sarkar A, Taraphdar D, Mukhopadhyay SK, Chakrabarti S, Chatterjee S: Serological and molecular diagnosis of Japanese encephalitis reveals an increasing public health problem in the state of West Bengal, India. Trans R Soc Trop Med Hyg 2012, 106:15-19.

29. Programme Implementation Plan 2011-12/National Rural Health Mission/Health and Family Welfare Department, West Bengal: Disease control programme: scheme/program under national rural health mission. http://pipnrhm-mohfw.nic.in/ index_files/non_high_focus_large/westbengal/4d.pdf. 
30. Westaway EG: Flavivirus replication strategy. Adv Virus Res 1987, 33:45-90

31. Luca VC, Abimansour J, Nelson CA, Fremont DH: Crystal structure of the Japanese encephalitis virus envelope protein. J Virol 2012, 86:2337-2346.

32. Rey FA, Heinz FX, Mandle C, Kunz C, Harrison SC: The envelope glycoprotein from tick-borne encephalitis virus at $2 \mathrm{~A}^{\circ}$ resolution. Nature 1995, 375:291-298.

33. Kolaskar AS, Kulkarni-Kale U: Prediction of three-dimensional structure and mapping of conformational epitopes of envelope glycoprotein of Japanese encephalitis virus. Virology 1999, 261:31-42.

34. Qi SC, Xiang ML, Qiao YZ, Dan DW, Huan CC, Ping Q: Isolation and molecular characterization of genotype 1 Japanese encephalitis virus, SX09S-01, from pigs in China. Virol J 2011, 8:472.

35. Zhang JS, Zhao QM, Guo XF, Zuo SQ, Cheng JX, Jia N, Wu C, Dai PF, Zhao $J Y$ : Isolation and genetic characteristics of human genotype 1 Japanese encephalitis virus, China, 2009. PLOS ONE 2011, 6:e16418.

36. Zhao Z, Date T, Li Y, Kato T, Miyamoto M, Yasui K, Wakita T: Characterization of the E-138 (Glu/Lys) mutation in Japanese encephalitis virus by using a stable, full-length, infectious cDNA clone. J Gen Virol 2005, 86:2209-2220.

37. Thomas PM, Arroyo J, Levenbook I, Zhang ZX, Catalan J, Draper K, Guirakhoo F: Single mutation in the flavivirus envelope protein hinge region increases neurovirulence for mice and monkeys but decreases viscerotropism for monkeys: relevance to development and safety testing of live, attenuated vaccines. J Virol 2002, 76:1932-1943.

38. Tajima S, Nerome R, Nukui Y, Kato F, Takasaki T, Kurane I: A single mutation in the Japanese encephalitis virus E protein (S123R) increases its growth rate in mouse neuroblastoma cells and its pathogenicity in mice. Virology 2010, 396:298-304.

39. Ni H, Barrett ADT: Molecular differences between wild-type Japanese encephalitis virus strains of high and low mouse neuroinvasiveness. J Gen Virol 1996, 77:1449-1455.

40. Ryuta K, Kar K, Anthony K, Gould LH, Ledizet M, Fikrig E, Marasco WA, Koski RA, Yorgo M: Crystal structure of West Nile virus envelope glycoprotein reveals viral surface epitopes. J Virol 2006, 80:11000-11008.

41. Beasley DW, Whiteman MC, Zhang S, Huang CY, Schneider BS, Smith DR, Gromowski GD, Higgs S, Kinney RM, Barrett AD: Envelope protein glycosylation status influences mouse neuroinvasion phenotype of genetic lineage 1 West Nile virus strains. J Virol 2005, 79:8339-8347.

42. Grant EN, Nelson CA, Chen BR, Diamond MS, Fremont DH: Crystal structure of the West Nile virus envelope glycoprotein. J Virol 2006, 80:11467-11474.

43. Sultana H, Foellmer HG, Neelakanta G, Oliphant T, Engle M, Ledizet M, Krishnan MN, Bonafé N, Anthony KG, Marasco WA, Kaplan P, Montgomery RR, Diamond MS, Koski RA, Fikrig E: Fusion loop peptide of the West Nile virus envelope protein is essential for pathogenesis and is recognized by a therapeutic cross-reactive human monoclonal antibody. J Immunol 2009, 183:650-660

44. Hopp TP, Woods KR: Prediction of protein antigenic determinants from amino acid sequences. Proc Natl Acad Sci 1981, 78:3824-3828.

45. Cherrier MV, Kaufmann B, Nybakken GE, Lok SM, Warren JT, Chen BR, Nelson CA, Kostyuchenko VA, Holdaway HA, Chipman PR, Kuhn RJ, Diamond MS, Rossmann MG, Fremont DH: Structural basis for the preferential recognition of immature flaviviruses by a fusion-loop antibody. EMBO J 2009, 28:3269-3276.

46. Takada K, Masaki H, Konishi E, Takahashi M, Kurane I: Definition of an epitope on Japanese encephalitis virus (JEV) envelope protein recognized by JEV-specific murine $\mathrm{CD}^{+}$cytotoxic T lymphocytes. Arch Virol 2000, 145:523-534.

47. Ni H, Barrett AD: Nucleotide and deduced amino acid sequence of the structural protein genes of Japanese encephalitis viruses from different geographical locations. J Gen Virol 1995, 76:401-407.

48. Lin CW, Wu SC: A functional epitope determinant on domain III of the Japanese encephalitis virus envelope protein interacted with neutralizing-antibody combining sites. J Virol 2003, 77:2600-2606.

49. Schuh AJ, Li L, Tesh RB, Innis BL, Barrett AD: Genetic characterization of early isolates of Japanese encephalitis virus: genotype II has been circulating since at least 1951. J Gen Virol 2010, 91:95-102.

50. Zhang S, Bovshik El, Maillard R, Gromowski GD, Volk DE, Schein CH, Huang CY, Gorenstein DG, Lee JC, Barrett AD, Beasley DW: Role of BC loop residues in structure, function and antigenicity of the West Nile virus envelope protein receptor-binding domain III. Virology 2010, 403:85-91.
51. Sidney J, Grey HM, Southwood S, Celis E, Wentworth PA, del Guercio MF, Kubo RT, Chesnut RW, Sette A: Definition of an HLA-A3-like supermotif demonstrates the overlapping peptide-binding repertoires of common HLA molecules. Hum Immunol 1996, 45:79-93.

52. Cocquerel $L$, Wychowski C, Minner F, Penin F, Dubuisson J: Charged residues in the transmembrane domains of hepatitis $C$ virus glycoproteins play a major role in the processing, subcellular localization, and assembly of these envelope proteins. J Virol 2000, 74:3623-3633.

53. Tang WF, Ogawa M, Eshita $Y$, Aono H, Makino $Y$ : Molecular evolution of Japanese encephalitis virus isolates from swine in Oita, Japan during 1980-2009. Infect Genet Evol 2010, 10:329-336.

54. Pujhari SK, Prabhakar S, Ratho RK, Modi M, Sharma M, Mishra B: A novel mutation (S227T) in domain II of the envelope gene of Japanese encephalitis virus circulating in North India. Epidemiol Infect 2011, 139:849-856.

doi:10.1186/1471-2334-13-368

Cite this article as: Sarkar et al:: Envelope protein gene based molecular characterization of Japanese encephalitis virus clinical isolates from West Bengal, India:

a comparative approach with respect to SA14-14-2 live attenuated vaccine strain. BMC Infectious Diseases 2013 13:368.

\section{Submit your next manuscript to BioMed Central and take full advantage of:}

- Convenient online submission

- Thorough peer review

- No space constraints or color figure charges

- Immediate publication on acceptance

- Inclusion in PubMed, CAS, Scopus and Google Scholar

- Research which is freely available for redistribution

Submit your manuscript at www.biomedcentral.com/submit
C Biomed Central 